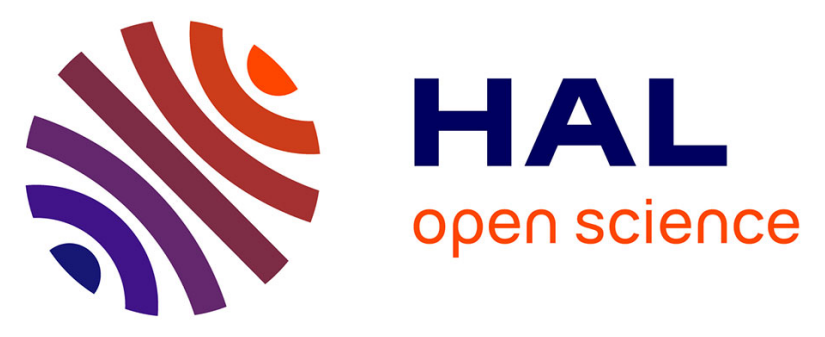

\title{
Primary alkyl bis-catecholato silicates in dual photoredox/nickel catalysis: aryl- and heteroaryl-alkyl cross coupling reactions
}

Christophe Lévêque, Ludwig Chenneberg, Vincent Corcé, Jean-Philippe Goddard, Cyril Ollivier, Louis Fensterbank

\section{To cite this version:}

Christophe Lévêque, Ludwig Chenneberg, Vincent Corcé, Jean-Philippe Goddard, Cyril Ollivier, et al.. Primary alkyl bis-catecholato silicates in dual photoredox/nickel catalysis: aryl- and heteroaryl-alkyl cross coupling reactions . Organic Chemistry Frontiers, 2016, 3 (4), pp.462-465. 10.1039/C6QO00014B . hal-01278421

\section{HAL Id: hal-01278421 \\ https: / hal.sorbonne-universite.fr/hal-01278421}

Submitted on 24 Feb 2016

HAL is a multi-disciplinary open access archive for the deposit and dissemination of scientific research documents, whether they are published or not. The documents may come from teaching and research institutions in France or abroad, or from public or private research centers.
L'archive ouverte pluridisciplinaire HAL, est destinée au dépôt et à la diffusion de documents scientifiques de niveau recherche, publiés ou non, émanant des établissements d'enseignement et de recherche français ou étrangers, des laboratoires publics ou privés. 


\title{
Primary Alkyl Bis-Catecholato Silicates in Dual Photoredox/Nickel Catalysis: Aryl- and Heteroaryl-Alkyl Cross Coupling Reactions
}

\author{
Christophe Lévêque, ${ }^{a}$ Ludwig Chenneberg, ${ }^{a}$ Vincent Corcé, ${ }^{a}$ Jean-Philippe Goddard, ${ }^{* b}$ \\ Cyril Ollivier* ${ }^{a}$ and Louis Fensterbank* ${ }^{a}$ \\ Primary alkyl bis-catecholato silicates have been successfully engaged with aryl and heteroaryl bromide substrates in \\ photoredox/nickel dual catalysis to provide aryl- and heteroaryl-alkyl cross coupling products. The scope of the \\ transformation is wide and the process appears to be tolerant of various functional groups present. Of note, most \\ examples rely on the challenging use of highly reactive primary radicals which constitutes a significant advance in these \\ cross coupling reactions.
}

Dedicated to John Murphy

Photoredox/nickel dual catalysis ${ }^{1,2}$ has recently emerged as a novel opportunity to form $\mathrm{C}-\mathrm{C}$ bonds and rapidly couple functionalized fragments for the elaboration of more complex molecules. ${ }^{3}$ A key advantage of this strategy is to merge the mildness of visible light photoredox catalysis for the generation of hot radical entities ${ }^{4}$ with the robustness of nickel catalyzed cross coupling reactions. ${ }^{5}$ While the electrophilic partner involved in the oxidative addition to nickel has so far consisted of aryl halides and related substrates, ${ }^{6}$ more functional variation has been brought on the radical source. To the best of our knowledge, all works have involved $\alpha$ amino, $^{2 \mathrm{~b}, 6,7} \alpha-O,{ }^{2 \mathrm{~b}, 6} \quad \alpha$-phenyl, ${ }^{2 \mathrm{~b}, 8} \quad \alpha$-oxo, ${ }^{9}$ and secondary ${ }^{6}$ carboxylic acids, mixed anhydrides, ${ }^{10}$ dimethylaniline, ${ }^{2 b}$ benzyl, $^{2 \mathrm{a}, 11}$ secondary ${ }^{2 \mathrm{a}, 9,12}$ and activated $(\alpha-O)$ primary trifluoroborates. ${ }^{13}$ More recently, potassium and ammonium bis-catecholato silicates have been reported by $\mathrm{us}^{14}$ as a valuable source of $\mathrm{C}$-centered radicals upon visible light photooxidation using $\operatorname{Ir}\left[\left(\mathrm{dF}\left(\mathrm{CF}_{3}\right) \text { ppy }\right)_{2}(\mathrm{bpy})\right]\left(\mathrm{PF}_{6}\right)$ as catalyst. The silicate substrates offer neat advantages over the related trifluoroborates in terms of solubility, of byproducts (no gas release, no fluoride, no boron) and of the scope of the possibly generated radicals (from stabilized alkyl ones to highly reactive primary ones). As a perspective, it was also found that they

\footnotetext{
a. Institut Parisien de Chimie Moléculaire, UMR CNRS 8232, Sorbonne Universités UPMC Univ Paris 06. 4 Place Jussieu, CC 229, F-75252 Paris Cedex 05, France. Email : cyril.ollivier@upmc.fr, louis.fensterbank@upmc.fr; Fax:+33(0)144277360

${ }^{b}$ Laboratoire de Chimie Organique et Bioorganique EA 4566, Université de HauteAlsace, Ecole Nationale Supérieure de Chimie de Mulhouse. 3 Bis rue Alfred Werner, 68093 Mulhouse Cedex, France. Email : jean-philippe.goddard@uha.fr. † Footnotes relating to the title and/or authors should appear here.

Electronic Supplementary Information (ESI) available: [details of any supplementary information available should be included here]. See DOI: $10.1039 / x 0 x x 00000 x$
}

could be engaged in photoredox/nickel dual catalysis for $\mathrm{C}_{s p 2^{-}}$ $\mathrm{C}_{s p 3}$ cross-coupling reactions, notably involving unstabilized primary radicals. ${ }^{14 a, 15}$

The limited sampling of these preliminary findings drove us to gain more insight into this transformation and define its scope by varying both partners (silicates and arylbromides, see Scheme 1). Subsequent to the first report of these cross coupling reactions by us, ${ }^{14 a}$ the group of Molander described similar transformations of related ammonium bis-catecholato secondary and primary alkyl silicates with aryl- and heteroarylbromides. ${ }^{16}$ Herein, we focus on primary radical intermediates and bring a complementary picture to these highly powerful reactions.

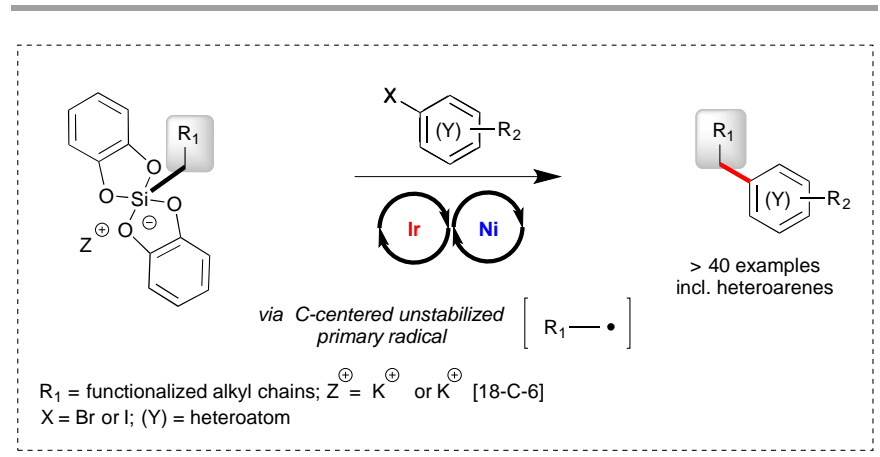

Scheme 1. Photoredox/nickel dual catalysis involving primary radicals from silicates

We first prepared a series of potassium silicates 1 . As found before, ${ }^{14}$ the latter are rendered rock stable by admixing the 18-C-6 crown ether additive. Nevertheless, we could show that 
this additive is not necessary to promote homolytic reactivity (see below). A preliminary screening of conditions with a given arylbromide, namely 4-bromoacetophenone $2 \mathrm{a}$ led us to the following protocol. To a DMF solution of silicate 1 (1.5 equiv, $0.1 \mathrm{M})$ in the presence of of $\operatorname{Ir}\left[\left(\mathrm{dF}\left(\mathrm{CF}_{3}\right) \text { ppy }\right)_{2}(\mathrm{bpy})\right]\left(\mathrm{PF}_{6}\right)$ (2 $\mathrm{mol} \%), \mathrm{Ni}(\mathrm{COD})_{2}(3 \mathrm{~mol} \%)$ and dtbbpy (3 mol\%) as ligand was added 4-bromoacetophenone 2a (1 equiv). After stirring for 24 $\mathrm{h}$ at $\mathrm{rt}$, excellent yields of coupling products 3aa-3ca were obtained from benzyl, allyl and $\alpha$-amino silicates (1a-c). Gratifyingly, less stabilized radicals could also be involved furnishing the corresponding coupling products 3 in $40-85 \%$ yields bearing various functional groups such as an ester (3ia, 3ja), a nitrile (3fa, 3ga) an oxirane (3ka, 3la) or a chloride (3ma). Interestingly, a comparison was made with the corresponding benzyltrifluoroborate precursor and showed in our conditions a more productive reaction (adduct 3aa) from the silicate 1a ( $88 \%$ vs. $58 \%$ yield). Also, potassium silicate $1 \mathbf{1}^{\prime}$ with no $18-\mathrm{C}-6$ also provided a good yield (86\%) of coupling product 3ia.

Table 1. Cross coupling reactions of silicates $\mathbf{1}$ with 4-bromoacetophenone $\mathbf{2 a}$
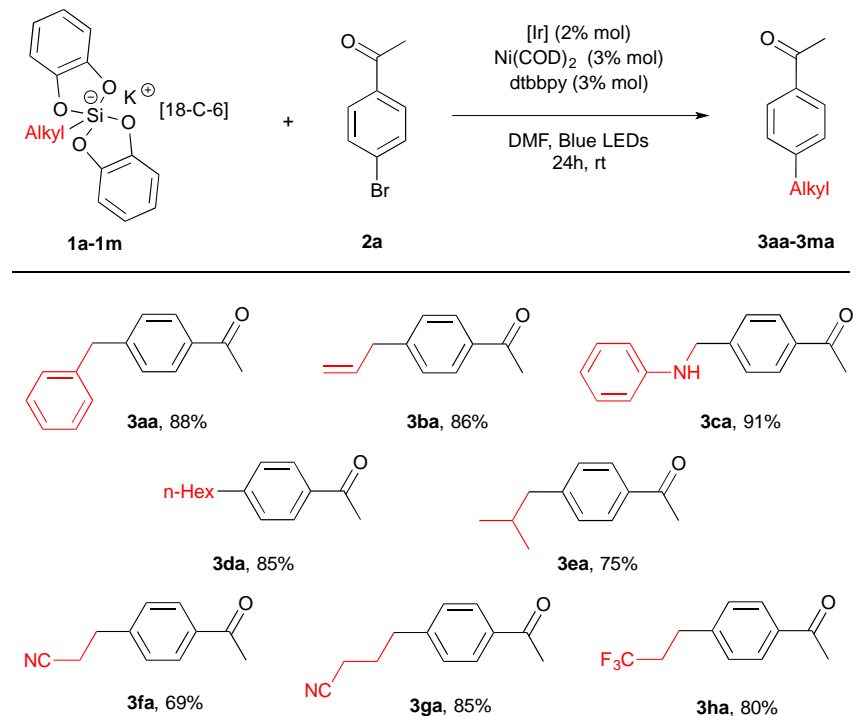

3fa, $69 \%$
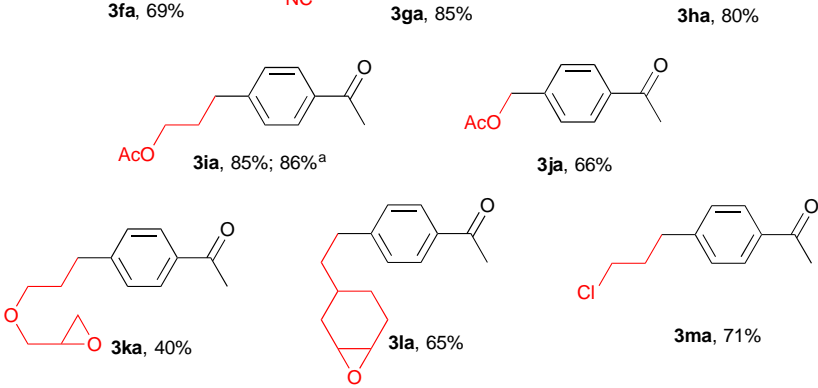

a Starting from the corresponding potassium silicate with no 18-C-6 1i' and 2a.

Using the same conditions, a series of arylbromides $\mathbf{2 a - 2 q}$ with varied substitution pattern could be used in conjunction with acetate silicate $\mathbf{1} \mathbf{i}$ or $\mathbf{1} \mathbf{i}$ ' (Table 2 ). First, reaction scope proved to be quite wide. Second, a closer examination of these results revealed interesting features. For instance, the difference of reactivity between a $\mathrm{C}_{s p 2}-\mathrm{Br}$ and a $\mathrm{C}_{s p 2}-\mathrm{I}$ bond was investigated with 1-bromo-4-iodobenzene $\mathbf{2 g}$. Not surprisingly, a preferred oxidative addition took place at the carbon-iodide bond ${ }^{17}$ giving a 10:1 ratio of products $\mathbf{3 i g}(X=B r)$ and 3ig' $(X=1)$. This appeared quite opportune for electron enriched aryl substrates. ${ }^{18}$ While meta-bromo anisoles ( $2 p$ and $\mathbf{2 q}$ ) could be effectively used (adducts 3ip and 3iq), only starting material was recovered with ortho-bromoanisole and parabromoanisole. The reluctant behavior of para-bromoanisole could be partly fixed by using the corresponding iodo derivative since cross coupling product 3io was obtained albeit in modest yield (46\%). These findings contrast with Molander's report $^{16 a}$ in which electron rich substrates proved to be competent. Their catalytic mixture $\left(5 \mathrm{~mol} \% \mathrm{NiCl}_{2}(\mathrm{dme}), 5\right.$ mol\% dtbbpy, 2 mol\% Ru(bpy $\left.)_{3}\left(\mathrm{PF}_{6}\right)_{2}\right)$ differs from ours (3 mol\% $\mathrm{Ni}(\mathrm{COD})_{2}, 3 \mathrm{~mol} \%$ dtbbpy and $2 \mathrm{~mol} \%$ $\left.\operatorname{Ir}\left[\left(\mathrm{dF}\left(\mathrm{CF}_{3}\right) \mathrm{ppy}\right)_{2}(\mathrm{bpy})\right]\left(\mathrm{PF}_{6}\right)\right)$ implying interesting metal and ligand effects that we are now investigating. ${ }^{18}$

Table 2. Cross coupling reactions of silicate $1 \mathrm{i}$ with various arylbromides
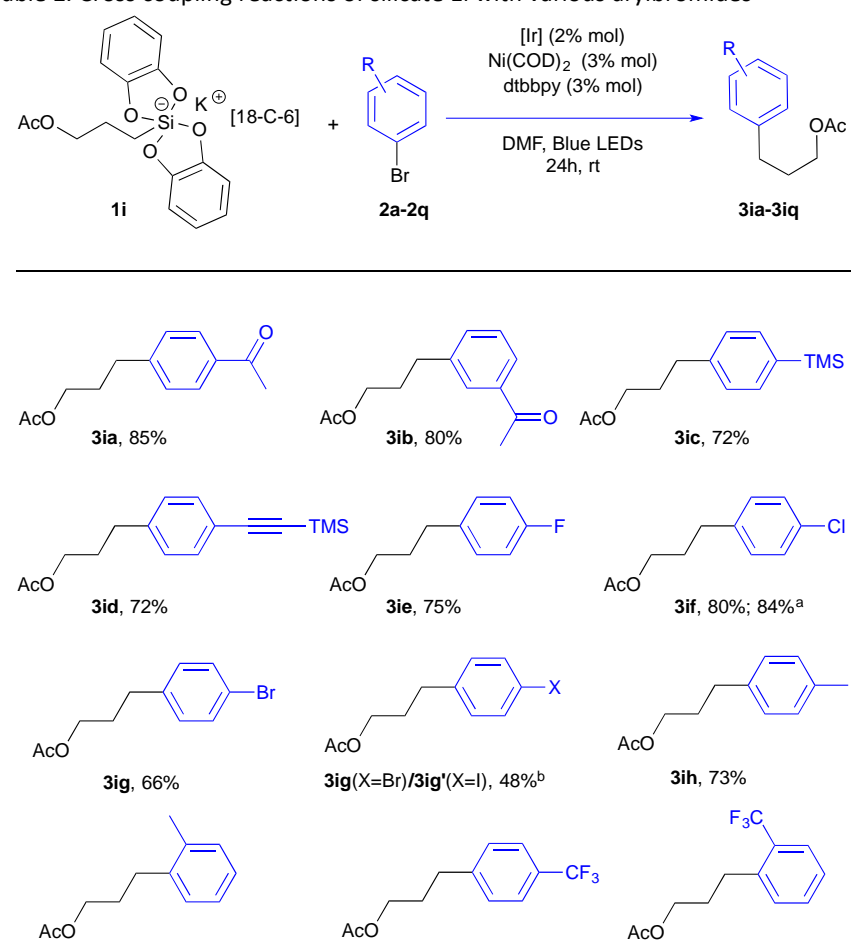

3ii, $76 \%$

$3 \mathrm{ij}, 94 \%{ }^{\mathrm{c} ;} ; 8 \%^{\mathrm{a}}$
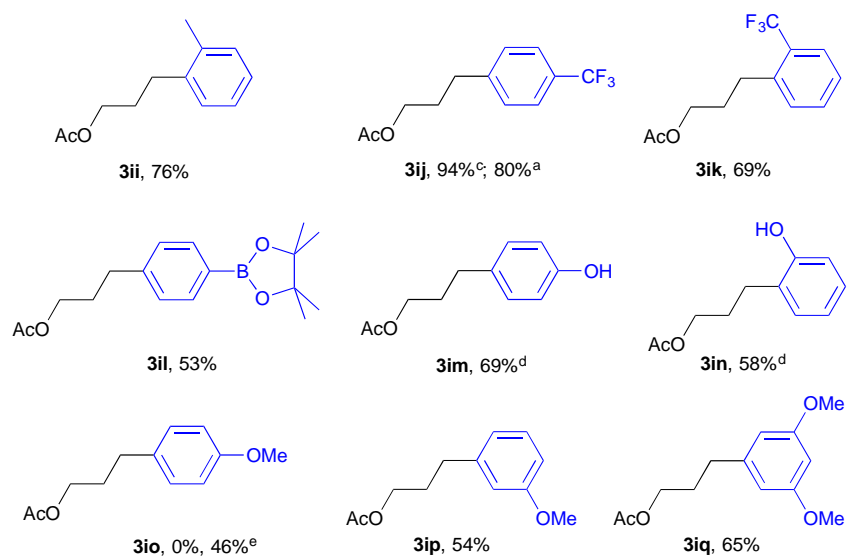

a Starting from the corresponding potassium silicate with no 18-C-6 1i'.

b Starting from 1-bromo 4-iodobenzene. A 10:1 mixture of 3ig and 3ig' was isolated.

${ }^{c} 2 \mathrm{~mol} \% \mathrm{Ru}(\mathrm{bpy})_{3}\left(\mathrm{PF}_{6}\right)_{2}$ was used instead of $2 \mathrm{~mol} \%[\mathrm{lr}]$.

d Pinacol borane directly oxidized before purification $\left(\mathrm{H}_{2} \mathrm{O}_{2}, \mathrm{NaOH}\right.$ for 30 min at $\left.0^{\circ} \mathrm{C}\right)$.

${ }^{\text {e }}$ Starting from 4-iodoanisole. 
Remarkably, a pinacol boronate function could also be tolerated in these conditions ${ }^{11}$ as illustrated by the formation of 3il that could be utilized for further coupling reactions. Nevertheless, direct isolation of this product after column chromatography was detrimental to the yield. Instead, when the crude reaction mixture was oxidized $\left(\mathrm{NaOH}, \mathrm{H}_{2} \mathrm{O}_{2}\right)$, a higher yield (69\% vs 53\% for 3il) of phenol product 3 im was recorded. Similar protocol was applied to give phenol product 3in.

Heterocyclic bromides completed the reach of this transformation and established its high synthetic potential. 2Fluoro-4-bromopyridine $\mathbf{2} r$ was used as partner of the dual catalysis in the presence of silicates $\mathbf{1 c}-\mathbf{m}$ and delivered a small library of new alkylpyridines $\mathbf{3 c r - 3 m r}$ in satisfactory yields

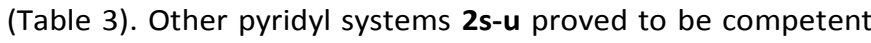
for this cross-coupling transformation. The corresponding products 3is-3iu were obtained in a $40-75 \%$ yield range. Finally, various heterocylic sytems such as quinoline $\mathbf{2 v}$, pyrimidine $\mathbf{2} \mathbf{w}$, indole $\mathbf{2 x}$, benzofuran $\mathbf{2 y}$ and thiophene $\mathbf{2 z}$ were engaged and yielded the corresponding cross coupling adducts $\mathbf{3}$ from mitigated to fair yields. ${ }^{19}$

Table 3. Cross coupling reactions of silicates $\mathbf{1}$ with various heterocyclic platforms.

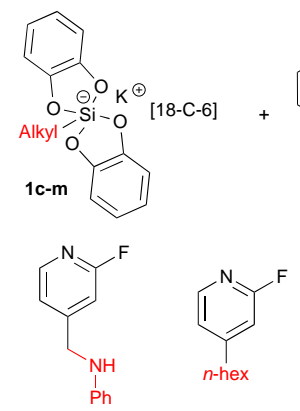

$3 \mathrm{cr}, 86 \%$

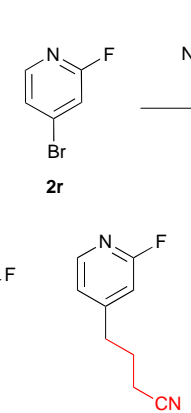

$3 \mathrm{gr}, 59 \%$
[Ir] $(2 \% \mathrm{~mol})$ $\mathrm{Ni}(\mathrm{COD})_{2}(3 \% \mathrm{~mol})$ dtbopy ( $3 \%$ mol)

\section{DMF, Blue LEDs} $24 h$, rt

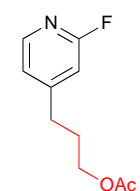

3ir, $81 \% ; 79 \%^{a}$

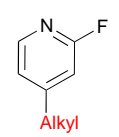

3cr-mr

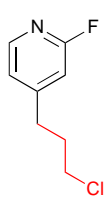

$\mathrm{C}$

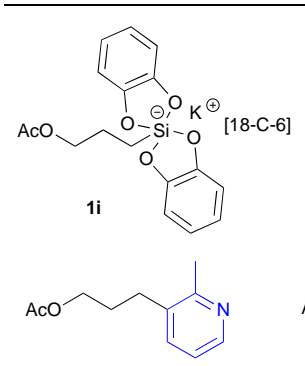

3is, $67 \%$<smiles></smiles>

3iv, $65 \%$
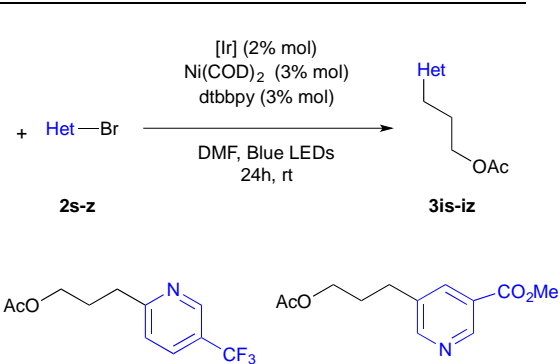

3it, $40 \%$

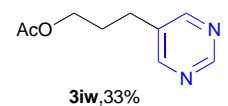<smiles>CC(=O)OCCCc1ccc2c(ccn2C)c1</smiles><smiles>COCCCc1ccc2occc2c1</smiles>

3iy , $73 \%$

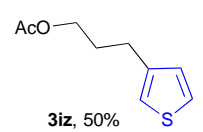

a Starting from the corresponding potassium silicate with no 18-C-6 1i'.

The proposed catalytic cycle is outlined in Scheme 2. It is well established that excitation of photoredox catalyst $\operatorname{Ir}\left[\left(\mathrm{dF}\left(\mathrm{CF}_{3}\right) \mathrm{ppy}\right)_{2}(\mathrm{bpy})\right]\left(\mathrm{PF}_{6}\right)$ produces a long-lived photoexcited state $* \operatorname{Ir}\left[\left(\mathrm{dF}\left(\mathrm{CF}_{3}\right) \mathrm{ppy}\right)_{2}(\mathrm{bpy})\right]\left(\mathrm{PF}_{6}\right)^{4}{ }^{4}$ The latter acts as a strong oxidant $\left(\mathrm{E}\left[{ }^{*} \mid \mathrm{Ir}^{\mathrm{II \prime} /} / \mathrm{Ir}^{\prime \prime}\right]=+1.32 \mathrm{~V} \text { vs SCE in } \mathrm{MeCN}\right)^{20}$ and undergoes a single electron transfer (SET) with bis-catecholato silicates 1 $\left(E_{o x} \text { between }+0.34 \text { and }+0.87 \mathrm{~V} \text { vs SCE in DMF }\right)^{14 a}$ generating a primary alkyl radical which interacts with a $\mathrm{Ni}$ species. However, the mechanism of this dual catalysis is still in debate. ${ }^{9,21}$ All proposals converge toward a $\mathrm{Ni}(\mathrm{III})$ intermediate which upon reductive elimination delivers the cross coupling product and a $\mathrm{Ni}(\mathrm{I})$ intermediate complex, the latter being further reduced $\left(\mathrm{E}\left[\mathrm{Ni}^{11} / \mathrm{Ni}^{0}\right]=-1.2 \mathrm{~V} \text { vs SCE in DMF }\right)^{22}$ by SET from the iridium(II) $\left(E\left[\mathrm{Ir}^{\mathrm{III}} / \mathrm{Ir}^{\mathrm{II}}\right]=-1.37 \mathrm{~V} \text { vs SCE in } \mathrm{MeCN}\right)^{20}$ to generate a $\mathrm{Ni}(0)$ complex. From this zero-valent nickel entity, two possibilities have been advanced. Initial oxidative addition of the ArX gives a $\mathrm{Ni}(I I)$ species that would trap the nucleophilic radical intermediate. Alternatively, an alkyl $\mathrm{Ni}(\mathrm{I})$ species would result from the trapping of the radical intermediate by $\mathrm{Ni}(0)$ followed by oxidative addition of the ArX to the $\mathrm{Ni}(\mathrm{III})$ intermediate (Scheme 2). Some of our results in Table 2 with the formation of $\mathbf{3 i g}$ and 3io highlight the importance of the oxidative addition step. However, this will necessitate more investigation to clarify that matter.

In conclusion, this study illustrates that bis-catecholato silicates are very reliable partners for photoredox/nickel dual catalysis. We have focused our efforts on the use of highly reactive primary radicals which so far has remained an uncharted territory. Our generally successful results in terms of yields and structure scope, since notably heteroatomic functions and heterocyclic platforms do not appear as limiting factors in these transformations, augur well for the application of this methodology in different settings.

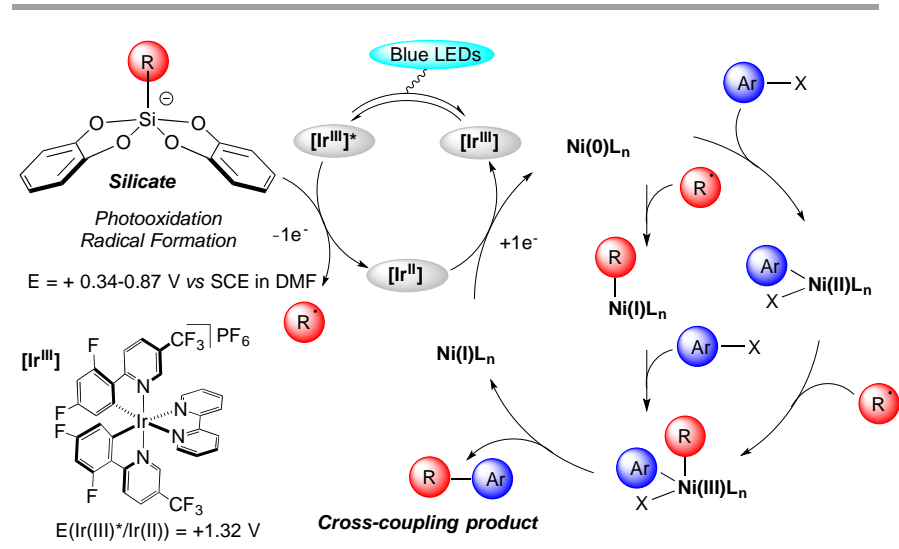

Scheme 2. Proposed mechanism of the photoredox/nickel dual catalysis using silicates

\section{Acknowledgements}

We warmly thank CNRS, UPMC, UHA, IUF, MSER (ASF PHD grant to $C L$ ), LABEX Michem (ANR-11-IDEX-0004-02), La Région Martinique (PhD grant to LC), ANR NHCX (11-BS07-008, 
postdoc grant to VC). COST Action CM1201 is gratefully acknowledged.

\section{Notes and references}

1 For a recent review on dual catalysis, see: (a) M. N Hopkinson, B. Sahoo, J.-L. Li and F. Glorius, Chem. Eur. J., 2014, 20, 3874; for recent reviews on dual photoredox/nickel catalysis, see: (b) C. Vila, ChemCatChem, 2015, 7, 1790; (c) J. J. Murphy and P. Melchiorre, Nature, 2015, 524, 297.

2 For seminal reports, see: (a) J. C. Tellis, D. N. Primer and G. A. Molander, Science, 2014, 345, 433; (b) Z. Zuo, D. T. Ahneman, L. Chu, J. A. Terret, A. G. Doyle and D. W. C. MacMillan, Science, 2014, 345, 437.

3 For C-O bond formation, see: (a) J. A. Terrett, J. D. Cuthbertson, V. W. Shurtleff and D. W. C. MacMillan Nature 2015, 524, 330; for C-P bond formation, see: (b) J. Xuan, T.-T. Zeng, J. R. Chen, L. Q. Lu and W. J. Xiao, Chem. Eur. J., 2015, 21, 4962.

4 For reviews and books, see: (a) J. M. R Narayanaman and C. R. J. Stephenson, Chem. Soc. Rev., 2011, 40, 102; (b) F. Teplý, Collect. Czech. Chem. Commun., 2011, 76, 859; (c) J. Xuan and W.-J. Xiao, Angew. Chem. Int. Ed., 2012, 51, 6828; (d) M. A. Ischay and T. P. Yoon, Eur. J. Org. Chem., 2012, 3359; (e) L. Shi and W. Xia, Chem. Soc. Rev., 2012, 41, 7687; (f) C. K. Prier, D. A. Rankic and D. W. C. MacMillan, Chem. Rev., 2013, 113, 5322; (g) D. P. Hari and B. König, Angew. Chem. Int. Ed., 2013, 52, 4734; (h) M. Reckenthäler and A. G. Griesbeck, Adv. Synth. Catal., 2013, 355, 2727; (i) T. Koike and M. Akita, Synlett, 2013, 24, 2492; (j) D. M. Schultz and T. P. Yoon, Science, 2014, 343, 985; (k) Chemical Photocatalysis, B. König, Ed., DeGruyter, Berlin, 2013; (I) Photochemically generated intermediates in Synthesis, A. Albini and M. Fagnoni, Eds., John Wiley \& Sons, Hoboken, 2013.

5 For reviews on nickel-catalyzed coupling reactions, see: (a) S. Z. Tasker, E. A. Standley and T. F. Jamison, Nature, 2014, 509, 299; (b) D. J. Weix, Acc. Chem. Res., 2015, 48, 1767; (c) V. P. Ananikov, ACS Catal., 2015, 5, 1964.

6 For vinylation, see: A. Noble, S. J. McCarver and D. W. C. MacMillan, J. Am. Chem. Soc., 2015, 137, 624.

7 M. El Khatib, R. A. M. Serafim and G. A. Molander, Angew. Chem. Int. Ed., 2016, 55, 254.

8 D. Ryu, D. N. Primer, J. C. Tellis and G. A. Molander, Chem. Eur. J., 2016, 22, 120.

9 L. Chu, J. M. Lipshultz and D. W. C. MacMillan, Angew. Chem. Int. Ed., 2015, 54, 7929.

10 C. C. Le and D. W. C. MacMillan, J. Am. Chem. Soc., 2015, 137, 11938.

11 Y. Yamashita, J. C. Tellis and G. A. Molander, Proc. Natl. Acad. Sci. U. S. A., 2015, 112, 12026.

12 D. N. Primer, I. Karakaya, J. C. Tellis and G. A. Molander, J. Am. Chem. Soc., 2015, 137, 2195.

13 I. Karakaya, D. N. Primer and G. A. Molander, Org. Lett., 2015, 17, 3294.

14 (a) V. Corcé, L. M. Chamoreau, E. Derat, J.-P. Goddard, C. Ollivier and L. Fensterbank, Angew. Chem. Int. Ed., 2015, 54, 11414; (b) For the oxidation of silicates with organic reagents, see also: L. Chenneberg, C. Lévêque, V. Corcé, A. Baralle, J.-P. Goddard, C. Ollivier and L. Fensterbank, Synlett 2016, DOI: $10.1055 / \mathrm{s}-0035-1561337$.

15 A primary carboxylic (5-phenylvaleric acid) has also been used as unstabilized radical precursor, providing the crosscoupling product but in $11 \%$ yield, see ref. 6 .

16 (a) M. Jouffroy, D. N. Primer and G. A. Molander, J. Am. Chem. Soc., 2016, 138, 475; (b) See also for vinylation: N. R.
Patel, C. B. Kelly, M. Jouffroy and G. A. Molander, Org. Lett. 2016, DOI: 10.1021/acs.orglett.6b00024.

17 J. F. Hartwig, Organotransition Metal Chemistry: From Bonding to Catalysis, University Science Books, Sausalito, 2009.

18 Cross coupling of $1 \mathrm{i}$ with 20 using, $3 \mathrm{~mol} \%$ of $\mathrm{NiCl}_{2}$. dme and 3 mol\% of dtbbpy, and $2 \mathrm{~mol} \%$ of $\operatorname{Ir}\left[\left(\mathrm{dF}\left(\mathrm{CF}_{3}\right) \text { ppy }\right)_{2}(\mathrm{bpy})\right]\left(\mathrm{PF}_{6}\right)$ provided $81 \%$ of 3io. For a recent discussion about the importance of the oxidation state of the nickel precatalyst, see: M. S. Oderinde, M. Frenette, D. W. Robbins, B. Aquila and J. W. Johannes J. Am. Chem. Soc., 2016, DOI: $10.1021 /$ jacs.5b11244.

19 The poor yields observed on 3it, 3iw and 3ix remain unexplained, since the crude products looked clean for each reaction.

20 D. Hanss, J. C. Freys, G. Bernardinelli and O. S. Wenger, Eur. J. Inorg. Chem., 2009, 4850.

21 (a) M. S. Oderinde, A. Varela-Alvarez, B. Aquila, D. W. Robbins and J. W. Johannes, J. Org. Chem., 2015, 80, 7642; (b) O. Gutierrez, J. C. Tellis, D. N. Primer, G. A. Molander and M. C. Kozlowski, J. Am. Chem. Soc., 2015, 137, 4896. (c) See also for a recent contribution: J. Cornella, J. T. Edwards, T. Qin, S. Kawamura, J. Wang, C.-M. Pan, R. Gianatassio, M. Schmidt, M. D. Eastgate and P. S. Baran, J. Am. Chem. Soc., 2016, DOI: 10.1021/jacs.6b00250.

22 M. Durandetti, M. Devaud and J. Perichon, New J. Chem., 1996, 20, 659. 